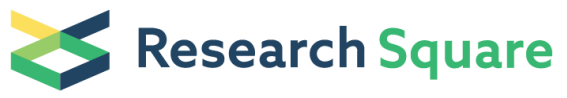 \\ Preprints are preliminary reports that have not undergone peer review. \\ They should not be considered conclusive, used to inform clinical practice, \\ or referenced by the media as validated information.
}

\section{Tonic Downward Movement of Eyes and Its Eccentric Positioning in Downgaze Under General Anaesthesia}

\author{
Shweta Chaurasia ( $\sim$ shweta84omns@yahoo.com ) \\ Post Graduate Institute of Medical Education and Research, Chandigarh, India \\ Shiv Lal Soni \\ Post Graduate Institute of Medical Education and Research, Chandigarh, India \\ Jagat Ram \\ Post Graduate Institute of Medical Education and Research, Chandigarh, India \\ Jaspreet Sukhija \\ Post Graduate Institute of Medical Education and Research, Chandigarh, India \\ Swati Chaurasia \\ Sanjay Gandhi Memorial Hospital, New Delhi \\ Aastha Takkar \\ Post Graduate Institute of Medical Education and Research, Chandigarh, India
}

\begin{abstract}
Research Article
Keywords: Down-rolling of eyes, eccentric eye positioning, down-gaze, minimal alveolar concentration, bispectral index, general anaesthesia, sevoflurane, muscle relaxants
\end{abstract}

Posted Date: March 31st, 2021

DOI: https://doi.org/10.21203/rs.3.rs-354044/v1

License: (c) (1) This work is licensed under a Creative Commons Attribution 4.0 International License. Read Full License 


\section{Abstract}

Objectives. To summarize abrupt eccentric eye positioning in downgaze following the downward movement of eyes encountered in patients undergoing ophthalmic surgeries under general anesthesia (GA) and analyze the relationship between the fluctuation in the depth of anesthesia (DOA) and eccentric eye positioning in downgaze.

Subjects and Methods. Patients undergoing ophthalmic surgeries under GA without nondepolarizing muscle relaxant between January 2018December 2019 in a tertiary-eye-care who witnessed a sudden tonic hypo-tropic movement of eyes were included in the retrospective, crosssectional study.

Results. A total of 8 patients out of 199 were enrolled in this study with an average age of $1.13 \pm 0.40 y$ ears. All cases (3 pediatric cataracts, 4 strabismus, and 1 pseudophakia with posterior capsular opacification) were performed under GA with sevoflurane as an inducing agent. Downward movement was seen before the start of surgery in 4 cases and during surgery in 4 cases. Downward drift of eyes appeared tonic as the strong tug was felt in an extreme downward eccentric position. It was preceded by an eccentric upward drift of eyes following which sevoflurane concentration was increased to optimize DOA when this downward drift was encountered (mean minimal alveolar concentration/MAC 1.63 \pm 0.25 ). Downward movement was quick but return movement of eyes to the central position was gradual (mean 1.55 \pm 0.48 minutes) when DOA was decreased (mean MAC 1.3 \pm 0.09$)$.

Conclusions. Tonic-downward movement of eyes or its eccentric positioning in downgaze is not an uncommon entity in children under GA without muscle-relaxant and fluctuations in DOA should be avoided to circumvent inadvertent complications during ocular surgery.

\section{Introduction}

Eye movement is an important guiding measure utilized by anesthetists to evaluate the depth of anesthesia. Eye movement generally ceases as the optimum depth of anesthesia is reached but is not uncommon to encounter eye movements on the table. For an ophthalmologist, eccentric eye movements can pose a surgical challenge due to constriction of the field of surgery and sudden jerk which can cause inadvertent complications at different steps of surgical procedures like cataract, squint, etc. So, all the extra-ocular muscles must remain relaxed while any ocular surgery is performed. Many authors have described slightly divergent and elevated eye positions during general anaesthesia. ${ }^{1,2,3,4}$ But only a few studies have described fixed eccentrically deviated eye positions during ocular surgery under general anesthesia and discussed its definite relationship with anesthetic depth. ${ }^{4,5,6} \mathrm{~A}$ quantitative examination of the relationship between eye elevation and anesthesia depth has found the shallower level of anesthesia to be related to a higher eye position. ${ }^{4,5,6}$ Deeper level of anesthesia-related to downward-position of eyes have been mentioned by few authors ${ }^{4,6}$ but there is paucity in the literature about detailed description and documentation of abrupt eccentric downward movement of eyes or eccentric down-positioning of eyes during ophthalmic surgery under general anaesthesia (GA). We here describe the tonic downward movement of the eyes and its eccentric positioning in downgaze which was encountered during surgery under general anesthesia without the use of muscle relaxants. These retrospective study aims to raise awareness regarding not so uncommon ocular finding occurring in children under certain general anesthesia conditions that have not been previously described but has notable implications in ophthalmic surgeries. Also, through the notable and interesting findings in our case series, we want to review the literature and find insight into the complexity of neuronal processes of sub-cortical structures controlling tonic eye movements under general anesthesia.

\section{Materials And Methods}

The study adhered to the tenets of the Declaration of Helsinki and the study was reviewed and approved by our Institutional Ethics committee of Postgraduate Institute of Medical Education and Research, Chandigarh, India. Operative records of 199 pediatric patients who underwent surgeries under general anesthesia with laryngeal mask airway without nondepolarizing muscle relaxant) between January 2018 and December 2019 were retrospectively reviewed and cases in which hypo-tropic movement was witnessed under direct observation during surgery were included in our study. Exclusion criteria were the unavailability of intra-operative details of eye movements and unrecorded values of anesthetic details at the time of eye movements. Written informed consent was obtained from all patients' parents or guardians regarding their study participation and publication of any identifying image. Anesthetic details including an anesthetic drug used as an induction agent, its concentration, and corresponding values of minimum alveolar concentration (MAC) ${ }^{7}$ of an anesthetic agent at the time of onset and sequence of events prior and following downward eye movements in different cases were noted. MAC is defined as the concentration of inhaled anesthetic within alveoli at which $50 \%$ of people show immobility in response to any nociceptive stimulus. MAC was employed as a reproducible metric to determine the adequacy of anesthetic dosing based on the assessment of a motor response to a surgical stimulus. Any oculocardiac reflex if present and any change in heart rate were noted. Types and duration of surgery were noted. The bispectral index (BIS) values if used and recorded were noted. BIS monitoring system used processed electroencephalography (EEG) parameters for measuring the hypnotic effect of anesthetic drugs on the central nervous system. ${ }^{8-11}$ BIS value has been validated for children $>2$ years to measure the depth of anaesthesia. ${ }^{9-11}$ The BIS value of 65 to 85 is recommended for sedation and a value of 40 to 65 for general anesthesia. ${ }^{8}$ 
Records of eccentric down-position of eyes either digital or physical documentation or both were evaluated and the vertical position of the eyes was scored on an ordinal scale from -3 to 0 , according to its height in relation to the medial canthus $(0=$ pupil position aligning medial canthus, $-1=$ only one-fourth cornea seen above the level of medial canthus, $-2=$ upper limbus in line with the level of the limbus, $-3=$ upper limbus just below the level of medial canthus with more than half of cornea visible, $-4=$ much below the level of medial canthus with less than half of cornea visible.

\section{Results}

A total of 10 patients were identified among a total of 199 children who underwent ophthalmic surgery under general anesthesia without muscle relaxants surveyed over 32 weeks between January 2018 and December 2019. But only 8 were included in the study as intra-operative anesthetic details were not available in rest. Mean age was $1.13 \pm 0.40$ years (range 8 months to $1.8 y e a r s)$. All cases were performed under general anesthesia using sevoflurane as an inducing agent with fentanyl $0.5-2 \mu \mathrm{g} / \mathrm{kg}$. The airway was maintained with a supraglottic airway device using sevoflurane, oxygen, and nitrous oxide (50:50) without a muscle relaxant. A BIS monitor (Aspect-2000; Aspect Medical Systems, Newton, MA, USA) and a BIS pediatric sensor (Aspect Medical Systems) were used to monitor anesthesia depth. Heart rate was maintained throughout and no oculocardiac reflex was noticed in the entire procedure in any of the cases. Among 8 cases, 3 were pediatric cataracts who underwent cataract surgery, 4 were infantile esotropia who received botulinum injection in both eyes of medial rectus, and 1 was pseudophakia with posterior capsule opacification (PCO) who underwent capsulotomy (Table 1). Down-rolling movement of eyes was seen (during surgery) in 4 cases (Fig. 1b) and down-drift was preceded by upward drift (on noxious stimuli) in all these 4 patients when the depth of anesthesia got lightened (Fig. 3). Documented mean MAC in 4 cases at the time of upward drift was 1.02 \pm 0.10 . Among these 4 patients, BIS was recorded in one, and documented BIS (in case 1 in which upward drift was seen) was 55 (Table 1). When anesthetists were made aware of the upward rolling of eyes, deepening of anaesthesia by increasing sevoflurane concentration was used as a measure in all cases to resolve the problem. Within a few minutes of increasing sevoflurane concentration, the eye returned to its primary position but as the procedure was re-started, eyes over-shooted in downgaze at the same time (Fig. 2). The downward movement caused the eye to acquire an eccentric eye position in downgaze. When the surgeons tried to manually rotate the eyes to the central position, difficulty was felt as the tonic downward force was experienced by the surgeons. The surgical procedure was abandoned for few minutes as a continuation of surgical procedure in its presence became unexpectedly difficult. The anesthetists were informed about the eccentric downward movement to which the anesthetist had no clue. Downward eccentric position of eyes was seen before the start of surgery after cleaning, draping, and putting eye speculum in 4 cases (Fig. 1a, Fig. 2, Figure,4a). 
Table 1

Details of 7 patients who encountered downward drift or had eccentric positioning of eyes in downgaze under general anesthesia without muscle relaxants.

\begin{tabular}{|c|c|c|c|c|c|c|c|c|c|c|}
\hline \multirow[t]{2}{*}{ case } & \multirow[t]{2}{*}{$\begin{array}{l}\text { Age } \\
\text { in } \\
\text { yrs }\end{array}$} & \multirow[t]{2}{*}{ Sex } & \multirow{2}{*}{$\begin{array}{l}\text { Type of Sx/dura of } \\
\text { Sx/No of surgeries } \\
\text { patient } \\
\text { underwent/episode } \\
\text { when down-rolling } \\
\text { occurred }\end{array}$} & \multirow[t]{2}{*}{$\begin{array}{l}\text { Inducing } \\
\text { agent }\end{array}$} & \multirow{2}{*}{$\begin{array}{l}\text { Any } \\
\text { Preceding } \\
\text { upward } \\
\text { drift/ }\end{array}$} & \multirow[t]{2}{*}{$\begin{array}{l}\text { Timing of } \\
\text { Downward } \\
\text { drift (B or } \\
\text { D or A) }\end{array}$} & \multirow{2}{*}{$\begin{array}{l}\text { HR during } \\
\text { Downshoot/ } \\
\text { any change } \\
\text { in HR or } \\
\text { OCR }\end{array}$} & \multirow[t]{2}{*}{$\begin{array}{l}\text { Change in } \\
\text { pupil size }\end{array}$} & \multirow{2}{*}{$\begin{array}{l}\begin{array}{l}\text { Duration } \\
\text { of } \\
\text { downshoot }\end{array} \\
\text { EYE } \\
\text { POSITION } \\
\text { SCORE }\end{array}$} & \multirow{2}{*}{$\begin{array}{l}\text { Details } \\
\text { when eye } \\
\text { centralized }\end{array}$} \\
\hline & & & & & & & & & & \\
\hline 1 & 1.4 & M & $\begin{array}{l}\text { Botox **/ } \\
\text { 20mins/3/ } \\
\text { 2nd }\end{array}$ & sevo & $Y / 1.1 / 55$ & $\mathrm{D} / 1.7 / 30$ & 152/None & $3.5 \mathrm{~mm} /$ none & $\begin{array}{l}1 \text { mins } 40 \\
\mathrm{sec} /-4\end{array}$ & $1.4 / 45$ \\
\hline 2 & 1.5 & M & $\begin{array}{l}\text { Botox**/20mins/ } \\
2 / 1 \text { st }\end{array}$ & sevo & No & $B / 1.6 / 34$ & 134/None & $2 \mathrm{~mm} /$ none & $\begin{array}{l}1 \min 10 \\
\mathrm{sec} /-3\end{array}$ & $1.3 / 50$ \\
\hline 3 & 1.8 & $M$ & $\begin{array}{l}\text { Cataract 15mins/ } \\
1 / 1 \text { st }\end{array}$ & sevo & $\mathrm{Y} / 1.1$ & $D / 1.8$ & 108/None & $\begin{array}{l}\text { Pupils } \\
\text { Dilated* }\end{array}$ & $\begin{array}{l}2 \text { minutes } \\
20 \mathrm{sec} /-4\end{array}$ & 1.4 \\
\hline 4 & $8 m$ & $\mathrm{~F}$ & $\begin{array}{l}\text { Cataract/15mins/ } \\
1 / 1 \mathrm{st}\end{array}$ & sevo & $\mathrm{Y} / 1$ & $D / 1.5$ & 110/None & $\begin{array}{l}\text { Pupils } \\
\text { dilated* }\end{array}$ & 1 minute-3 & 1.2 \\
\hline 5 & 1 & $\mathrm{~F}$ & $\begin{array}{l}\text { capsulotomy/ } \\
\text { 15minutes/2/2nd }\end{array}$ & sevo & $Y / 0.9$ & $\mathrm{D} / 1.4$ & 120/None & $\begin{array}{l}\text { Pupils } \\
\text { dilated* }\end{array}$ & $\begin{array}{l}1 \mathrm{~min} 45 \\
\mathrm{sec} /-3\end{array}$ & 1.3 \\
\hline 6 & 1.1 & $\mathrm{~F}$ & 10minutes/1/1st & sevo & No & $\mathrm{B} / 2$ & 120/None & $2 \mathrm{~mm} /$ none & 2 mins/-2 & 1.2 \\
\hline 7 & $9 m$ & M & $\begin{array}{l}\text { Cataract surgery/ } \\
15 \text { minutes/2/1st }\end{array}$ & sevo & $\mathrm{Y} / 1$ & $\mathrm{~B} / 1.8$ & 130/None & $\begin{array}{l}\text { Pupil } \\
\text { dilated* }\end{array}$ & $\begin{array}{l}1 \text { minute30 } \\
\text { seconds/-3 }\end{array}$ & 1.4 \\
\hline 8 & $10 \mathrm{~m}$ & M & $\begin{array}{l}\text { Botox }{ }^{\star *} \\
\text { 10minutes/1/1st }\end{array}$ & sevo & No & $B / 1.4$ & 146/None & $1.4 \mathrm{~mm} /$ none & 1minute/-2 & 1.2 \\
\hline $\begin{array}{l}\text { Yrs = } \\
\text { bispec }\end{array}$ & s; $n$ & $\begin{array}{l}\text { nont } \\
3=b\end{array}$ & $\begin{array}{l}; M=\text { male; } F=\text { fema } \\
\text { ore start of surgery; }\end{array}$ & $\begin{array}{l}\text { Sx }=\text { surs } \\
\text { during } s\end{array}$ & $\begin{array}{l}\text {; sevo = se } \\
\text { ery or after }\end{array}$ & $\begin{array}{l}\text { urane; } Y= \\
\text { int of surg }\end{array}$ & $\begin{array}{l}\mathrm{N}=\text { no; } M A C \\
\mathrm{HR}=\text { heart } \mathrm{rc}\end{array}$ & $\begin{array}{l}\text { ninimal alve } \\
\text { OCR = oculo- }\end{array}$ & $\begin{array}{l}\text { Ir concentrator } \\
\text { rdiac reflex; }\end{array}$ & ; BIS- \\
\hline *Pup & were & arma & ogically dilated & & & & & & & \\
\hline
\end{tabular}

Adequate depth of anesthesia was noted in all 8 cases when eyes were found in extreme down-drifted positions. Mean eye scoring in downgaze was $-3 \pm 0.76$. All eyes were slightly adducted during eccentric positioning in downgaze (opposite of upward and outward positioning in up-gaze). Documented mean MAC in 8 cases at the time of eccentric movement in downgaze was $1.63 \pm 0.25$ while measured BIS in 2 cases were 30 and 34 (Table 1). Anesthetist decreased the depth of anesthesia slightly on a trial basis by decreasing the volatile agent. Eccentric downgaze eye position was maintained till anesthetic depth was lightened (as indicated by decreased mean MAC $=1.3 \pm 0.09$ ) and then eyes returned to their resting 
position. Propracaine was given in all patients before the start of the procedure and the mean pupil size was $2.22 \mathrm{~mm}$ in 4 squint patients at the time of the start of the procedure before the episode of upward drift and no further change in pupil size was noted through-out. Rest 4 patients' pupils were pharmacologically dilated. Tonic downward movement was quick (spanning few seconds) but the return was slow over few minutes (mean time $1.55 \pm 0.48$ minutes) which partially interrupted the ongoing surgical procedure till the depth of anesthesia was balanced to make the eye return to its resting position. Further decrease in depth of anesthesia slowly drifted upward at the time when surgery was terminated. All the movements were and smooth through-out. No complications were encountered as fortunately during the movements no instruments were not close to important structures of the eye. Among 8 patients, 4 patients (Table 1; case1,2,5,7) underwent repeat surgeries under GA without NMDR but the downward drift was seen on only one occasion. (during 2 nd procedure out of 3 in case 1,1 st procedure out of 2 in case 2 , 2nd procedure out of 2 in case5 and 7). Downward drift was symmetrical in both eyes except case7 in which down-ward scoring of right was more than left eye (Fig. 2a). Preoperative records of that patient (case7) showed left eye dissociated vertical deviation (Fig. 2b).

\section{Discussion}

Eye movements under general anaesthesia have always generated great interest. In 1848 Snow ${ }^{12}$ defined the concept of anesthetic depth and defined the cessation of voluntary eye movement and inclination of eyes in up-gaze as the point of sufficient anesthetic depth. Using the degree of etherization, Guedel ${ }^{13}$ described the various stages of anaesthesia. Stages 1 and 2 relate to the induction of anaesthesia and stage 3 corresponds to the stage of 'surgical anaesthesia' the ideal state for most surgeries which he further divided into 4 planes. During plane 1 there is somatic relaxation, loss of blink reflex but marked roving movement of eyeballs and this plane ends as eyeball movement cesses. Plane 2 is characterized by fixed eyeballs (eccentric eye position) and loss of a corneal reflex. In deeper planes (3 and 4) pupillary reflex is lost, pupils are dilated and extraocular muscles became flaccid.

Eccentric eye positioning under general anaesthesia is not uncommon. Though few studies have described up-gaze eccentric eye-positioning under general anesthesia, there is paucity in literature regarding eccentric down positioning of eyes. ${ }^{4,5,6,14}$ Few of the studies describing eye positioning under general anesthesia encountered down positioning of eyes.,6,14 Power et al in his study observed final eye position in downward direcion under different depths of general anesthesia ${ }^{14}$ in few patients but their number, depth of general anaesthesia, and down-scoring of eye position were never described. In his study of 32 patients, Chung et al ${ }^{6}$ encountered elevation of the eyes in $83 \%$, and down-shoot of eyes was noted in $2 \%$. Down-shoot eye movement was seen at BIS values less than 35 . They also studied the relationship between fixed eccentric eye elevation and depth of anaesthesia during surgery and scored the vertical position of each eye on an ordinal scale from -2 to +6 , according to its height in relation to the medial canthus. ${ }^{6}$ Only one child ( $2 \%$ ) out of 32 children developed downward drift. ${ }^{6}$ To our knowledge no study has ever studied the downrolling of eyes preceded by up-rolling and compared it with the increase or decrease of anesthetic concentration and their corresponding MAC values. Also, no study has described scoring of eccentric down-rolling of eyes up-to inferior fornix and has discussed the entity in detail.

In our case series, this tonic downward movement was seen in pediatric cases (< 2 years) under sevoflurane general anaesthesia without muscle relaxant when attempts were made to rapidly deepen/optimize the plane of anaesthesia (on surgeon's request to centralize eye position from eccentric positioning in up-gaze) or at the beginning of surgery. Under all occasions, at the time eccentric fixation of eyes in downgaze, and adequately deeper plane of anaesthesia was found as demonstrated by the higher value of MAC in all cases (Table 1). The lower value of BIS (in case1) corroborated the finding of the prior studies ${ }^{4,6}$ though values of BIS in children infants and young children do not indicate a similar concentration of sevoflurane like adults. ${ }^{15}$ Down-movement of eyes to eccentric position towards inferior fornix was fast but the return of downmovement was smooth and gradual lasting over few minutes till the depth of anaesthesia was comparatively lightened by decreasing the flow of sevoflurane and eye reached to the central position. Its occurrence made surgeons abandon the procedure till the time it lasted. It appeared to have resulted from a tonic contraction of the inferior rectus of both eyes as it was difficult to manually rotate the eyes and carry the procedure. All cases had symmetric down-rolling (Fig. 4) except case 6 in which asymmetry was evident (Fig. 3). Though we could not understand the exact reason we suspected asymmetric dissociated vertical deviation in the child to alter the eye position.

The nerve impulses that generate the motor discharge in the form of a saccade originate as two types: burst neurons and tonic neurons. ${ }^{16}$ Highfrequency bursts of action potentials beginning before the commencement of the saccade and ending just before the eye movement are produced by burst neurons whereas tonic neurons discharge at regular intervals to hold the eye in the new eccentric position. In our case series, the hypotropic movement appeared both as a result of pulse firing which caused the eye to achieve rapid saccade velocity in downgaze and tonic firing which held the eye in the downward eccentric position till the anaesthesia was lightened.

Most authors have described eccentric positioning of eyes under GA in upgaze. ${ }^{4,5,6,12}$ Power et al while studying the depth of anaesthesia in young adults via sevoflurane induction compared eye signs with EEG polysomnography and showed that, the deepest level of sleep was reached on an average 3 minutes before the onset of eccentric ocular positioning thereby suggesting that eccentric eye movements may occur even when a patient appears satisfactorily anesthetized. ${ }^{14}$ Rossiter reported an incidence of $8 \%$ which increased up-to $18 \%$ without the use of muscle relaxants. ${ }^{5}$ Higher incidence of up-gaze eccentric movement (34.4\%) in Kook's study was due to an extended duration of the measurement period, including the time of emergence from anaesthesia ${ }^{4}$ as upward eye positioning is more commonly seen at the end of surgery when anaesthesia is lightened. Few 
authors quantified eye position related to the depth of anesthesia using BIS and found a shallower level of anaesthesia to be associated with a higher BIS value and a higher eye position. ${ }^{4,6}$ In our case series also upward drifting of the eyeball was seen under lighter planes of anesthesia during eye manipulation during surgery as demonstrated by lower MAC values (mean 1.03 \pm 0.10 ) in 4 patients in which upward drift was seen during surgery. High BIS value (55) recorded in case1 corroborated the findings of the prior studies. ${ }^{4,6}$

Inhalational agents are known to cause a dose-dependent suppression of reflexes and movements. ${ }^{1}$ Complete lack of electrical discharge in the extraocular muscles occurs only during deep sleep or deep anaesthesia. ${ }^{1}$ Presence of electrical activity in one of the extraocular muscles occurs over its opposing muscle in the lighter plane of anaesthesia and probable causation has been discussed in the literature by many researchers. Rossiter et al reasoned intense and sustained contraction of superior rectus (SR) behind the eccentric upward eye position. ${ }^{5}$ Harrad and Stoddart ${ }^{17}$ suggested that Bell's phenomenon, a natural protective reflex, in which the globe rolls up in response to any noxious stimuli in the form of pressure on the globe or any manipulation of the eyeball may explain this upward eccentric eye position. ${ }^{18,19}$ This occurs both in the awake state and with lighter planes of anaesthesia (though the patient is not awake) which may explain the entity. The exact neural mechanism is unknown but involves brainstem pathways between the seventh cranial nerve nucleus in the pons and the third cranial nerve nuclear complex in the rostral midbrain. Hiraoka et al have suggested that the mesencephalic reticular nucleus may play an important role in integrating these two patterns of movement (bilateral lid closure and upward movement of both eyes). ${ }^{20}$ Bell's reflex is also extinguished with deep planes of anaesthesia such that the eye remains in the neutral gaze. ${ }^{16,17}$ And this upward drift in cases 2, 3, and 4 prompted the anesthetist to increase the depth of anesthesia to make the eyes return from the upward position following which down-rolling was encountered.

The causation of down-rolling has never been discussed. We hypothesize that the probable reason for such down-rolling movement could be due to temporary irritative effects in the central nervous system related to the used anesthetic agent as in all our observations eye movements altered as per the level of MAC. It is a norm to increase sevoflurane concentration for smooth intubation and it is lowered to a chosen value following intubation. And the causes of irritative effect can be two-fold though we need further research with prospective studies to investigate the same. First, it could be due to of sudden increase in sevoflurane concentration (higher MAC) and differential sensitivity of cortical and subcortical centers for different sevoflurane concentrations. ${ }^{21}$ Higher MAC means a higher level of an anesthetic agent within alveoli and, in turn, a higher level in the central nervous system. Mourisse and colleagues ${ }^{22}$ have demonstrated in adults that the blink reflex (brainstem function) was more sensitive to sevoflurane than BIS (forebrain function), To date, few available pediatric data have investigated the relative effect of anaesthesia on cortical and subcortical site controlling eye movements. The meso-diencephalic junction contains the rostral interstitial nucleus of the medial longitudinal fasciculus, the interstitial nucleus of Cajal, the mesencephalic reticular formation, and the posterior commissure, all of which are involved in premotor control of vertical eye movements. ${ }^{23}$ Forced downward gaze is common in the lesions affecting this area and presumably represents an imbalance in the vertical gaze plane. ${ }^{24}$ Downward deviation in our cases could be caused by a rapid increase in sevoflurane concentration and selective irritation of downgaze neurons in the midbrain. ${ }^{25,26}$ Its occurrence only in certain children can be explained by the varied sensitivity of different individuals and lower sensitivity of sevoflurane for some subcortical structures (i.e. mesencephalic control) in prepubertal children than older subjects. ${ }^{21}$ Its occurrence only on a certain occasion in the same child could be time interval and the deeper plane of anesthesia to which child was subjected during intubation and chosen value of MAC to which patient was stabilized before handing over the child to the ophthalmic surgeon for the procedure. It should be noted that though the mean MAC value in case 8 when down-rolling was encountered before the start of the procedure was only 1.4 transient MAC values during the process of intubation was much higher (1.7) and as per the experience of authors it takes few minutes for the eyes to respond to increased or decreased sevoflurane concentration and eyes centration response comes when MAC level below their corresponding threshold is reached though further studies are needed to confirm the same

Another plausible reason could be due to transient drop in perfusion pressure below the lower limit in small children due to shortened autoregulation and vasodilatory effect of sevoflurane causing transient decreased cerebral blood flow (CBF) and irritative effect which get reversed on decreasing the concentration. ${ }^{27,28}$ Lower limits of autoregulation in sevoflurane anaesthesia is close to the baseline mean arterial pressure of young children. ${ }^{29}$ This hypothesis is supported by the finding that hypo-tropic movement in our cases was seen at or beyond $1.5 \mathrm{MAC}$ as $\mathrm{CBF}$ in young children remain unaffected up-to 1.5 MAC value of sevoflurane. ${ }^{27,30}$ Its selective occurrence at one particular exposure out of multiple exposures/subjugations to general anesthesia (case1) probably point towards violation of narrow autoregulation limit when depth got deepened beyond the permissible limit for the child depending on hid individual sensitivity window at the time of particular exposure. The territory of the posterior circulation supplying mesencephalic-diencephalic junction, which contains structures important for vertical gaze and vergence could be an affected area that has been associated with tonic downward and inward movement ${ }^{30}$ as seen in our cases. Though rarely at higher concentration (5.3\%) of sevoflurane, tonic-clonic movements have been described ${ }^{32}$ but the concentrations at which these hypo-tropic movements were seen in our cases, routinely and necessarily does not lead to cerebral ischemia in healthy children as thousands of sevoflurane inductions are performed every day in children, and neurologic complications are very rare. Eccentric movement of eyes on one occasion and not every time the same patient is taken under general anesthesia implies that the movement happened only when MAC level fell below or high beyond the narrow limit in the sensitive children.

This report aims to sensitize ophthalmologists regarding this sudden eye movement encountered under general anaesthesia and suggests the use of muscle relaxants in ophthalmic surgeries with critical steps like cataracts, squint, etc. Also, our case series highlight the importance of

Page 6/10 
maintaining required depth of anaesthesia without fluctuation if GA given without muscle-relaxant for short procedures. We need further studies on the detailed evaluation of eccentric downgaze or hypo-tropic movement including eye movement tracking devices or recordings and its relationship with eccentric upward position and depth of anaesthesia (using BIS and MAC values). Also, via electro-oculographic records of eye movements, simultaneous EEG, and clinical observations we need to investigate the tonic force in the inferior rectus to understand the pathophysiology of these eye movements giving clue into ongoing sub-cortical processes. It will also be interesting to further study why certain children develop the extreme eccentricity of eyes in downgaze and if an anesthetic agent has a role in these movements. The entity also requires attention for further investigations regarding its relationship with the depth of anaesthesia and age of the child.

\section{Declarations}

\section{Financial support-}

None

\section{Proprietary interest statement (on behalf of each author)-}

The authors have no proprietary interest in any of the materials used in our study.

\section{References}

1. von Noorden GK, Campos EC. Classification of neuromuscular anomalies of the eyes. In: von Noorden GK, Campos EC. Binocular vision and ocular motility: theory and management of strabismus. 6th ed. St. Louis: CV Mosby, 2002.p. 110-28.

2. Apt L, Isenberg S. Eye position of strabismus patients under general anesthesia. Am J Ophthalmol. 1977 Oct;84(4):574-9. doi: 10.1016/00029394(77)90455-x. PMID: 910863.

3. Castanera de Molina A, Giner Muñoz ML. Ocular alignment under general anesthesia in congenital esotropia. J Pediatr Ophthalmol Strabismus. 1991 Sep-Oct;28(5):278-82. PMID: 1955965.

4. Kook KH, Chung SA, Park S, Kim DH. Use of the Bispectral Index to Predict Eye Position of Children during General Anesthesia. Korean J Ophthalmol 2018 Jun;32(3):234-240.

5. Rossiter JD, Wood M, Lockwood A, Lewis K. Operating conditions for ocular surgery under general anaesthesia: an eccentric problem. Eye (Lond) 2006;20:55-8.

6. Seung Ah Chung, Seran Jang, Koung Hoon Kook, Jong Bok Lee; Prediction of eye position during general anesthesia using bispectral index monitoring. Ophthalmol. Vis. Sci.2014;55(13):2560.

7. Eger El, Saidman LJ, Brandstater B. Minimum alveolar anesthetic concentration: a standard of anesthetic potency. 1965 Nov-Dec;26(6):756-63.

8. Sebel PS, Lang E, Rampil IJ, et al. A multicenter study of bispectral electroencephalogram analysis for monitoring anesthetic effect. Anesth Analg 1997;84:891-9.

9. McCann ME, Bacsik J, Davidson A, et al. The correlation of bispectral index with end tidal sevoflurane concentration and haemodynamic parameters in pre-schoolers. Paediatr Anaesth 2002;12:519-25.

10. Denman WT, Swanson EL, Rosow D, et al. Pediatric evaluation of the bispectral index (BIS) monitor and correlation of BIS with end-tidal sevoflurane concentration in infants and children. Anesth Analg 2000;90:872-7.

11. Ganesh A, Watcha MF. Bispectral index monitoring in pediatric anesthesia. Curr Opin Anaesthesiol. 2004;17:229-34.

12. Snow JD. On the inhalation of the vapour of ether in surgical operations. Br J Anaesth 1953;25:253-67.

13. Guedel AE. Inhalation anaesthesia: a fundamental guide. 1st ed. Macmillan: New York; 1937. p. 63-4.

14. Power C, Crowe C, Higgins P, Moriarty DC. Anaesthetic depth at induction: an evaluation using clinical eye signs and EEG polysomnography. Anaesthesia 1998; 53: 736-743.

15. Sciusco A, Standing JF, Sheng Y, Raimondo P, Cinnella G, Dambrosio M. Effect of age on the performance of bispectral and entropy indices during sevoflurane pediatric anesthesia: a pharmacometric study. Paediatr Anaesth. 2017 Apr;27(4):399-408.

16. Griffiths AN, Marshall RW, Richens A. Saccadic eye movement analysis as a measure of drug effects on human psychomotor performance. Br J Clin Pharmacol 1984;18 Suppl 1(Suppl 1):73S-82S.

17. Harrad RA, Stoddart P. Operating conditions for ocular surgery under general anaesthesia: an eccentric problem. Eye (Lond) 2007;21:256-7.

18. Bell C. On the motions of the eye in illustration of the uses of the muscles and nerves of the orbit. Philos Trans Royal Society of Lond 1823; 113: $166-86$.

19. Francis IC, Loughhead JA. Bell's phenomenon. A study of 508 patients. Australian Journal of Ophthalmology 1984; 12: 15-21

20. Hiraoka M. Physiological study of the Bell's phenomenon in human. (Japan). Acta SOC Ophthalmol Japan 1979; 83: $2184-90$. 
21. Bourgeois E, Sabourdin N, Louvet N, et al. Minimal alveolar concentration of sevoflurane inhibiting the reflex pupillary dilatation after noxious stimulation in children and young adults. British Journal of Anaesthesia 2012 Apr;108(4):648-654

22. Mourisse J, Lerou J, Struys M, Zwarts M, Booij L. Multi-level approach to anaesthetic effects produced by sevoflurane or propofol in humans: 1. BIS and blink reflex. Br J Anaesth 2007;98(6):737-45.

23. Bhidayasiri R, Plant GT, Leigh RJ. A hypothetical scheme for the brainstem control of vertical gaze. Neurology 2000;54:1985-1993.

24. Keane JR. The pretectal syndrome: 206 patients. Neurology. 1990;40:684-690.

25. Sharpe JA: Neural control of ocular motor systems; in Miller NR, Newman NJ (eds): Walsh and Hoyt's Clinical Neuro-Ophthalmology, 5th edn. (Baltimore, Williams \& Wilkins, 1998) vol 1, pp 1101-1188.

26. Pierrot-Deseilligny C, Chain F, Gray F, Serdaru M, Escourolle R, Lhermitte F: Parinaud's syndrome: Electro-oculographic and anatomical analyses of six vascular cases with deductions about vertical gaze organization in the premotor structures. Brain. 1982;105:667-696.

27. Rhondali O, Mahr A, Simonin-Lansiaux S, De Queiroz M, Rhzioual-Berrada K, Combet S, Cejka JC, Chassard D. Impact of sevoflurane anesthesia on cerebral blood flow in children younger than 2 years. Paediatr Anaesth. 2013 Oct;23(10):946-51

28. Goettel N, Patet C, Rossi A, Burkhart CS, Czosnyka M, Strebel SP, Steiner LA. Monitoring of cerebral blood flow autoregulation in adults undergoing sevoflurane anesthesia: a prospective cohort study of two age groups. J Clin Monit Comput. 2016 Jun;30(3):255-64.

29. Vavilala MS, Lee LA, Lam AM. The lower limit of cerebral autoregulation in children during sevoflurane anesthesia. J Neurosurg Anesthesiol. 2003; 15: 307-312

30. Fairgrieve R, Rowney DA, Karsli C et al. The effect of sevoflurane on cerebral blood flow velocity in children. Acta Anaesthesiol Scand. 2003; 47: 1226-1230

31. Choi KD, Jung DS, Kim JS. Specificity of "peering at the tip of the nose" for a diagnosis of thalamic hemorrhage. Arch Neuro/ $2004 ; 61: 417-422$.

32. Szabo EZ, Luginbuehl I, Bissonnette B. Impact of anesthetic agents on cerebrovascular physiology in children. Pediatr Anesth 2009; 19: 108118.

\section{Figures}
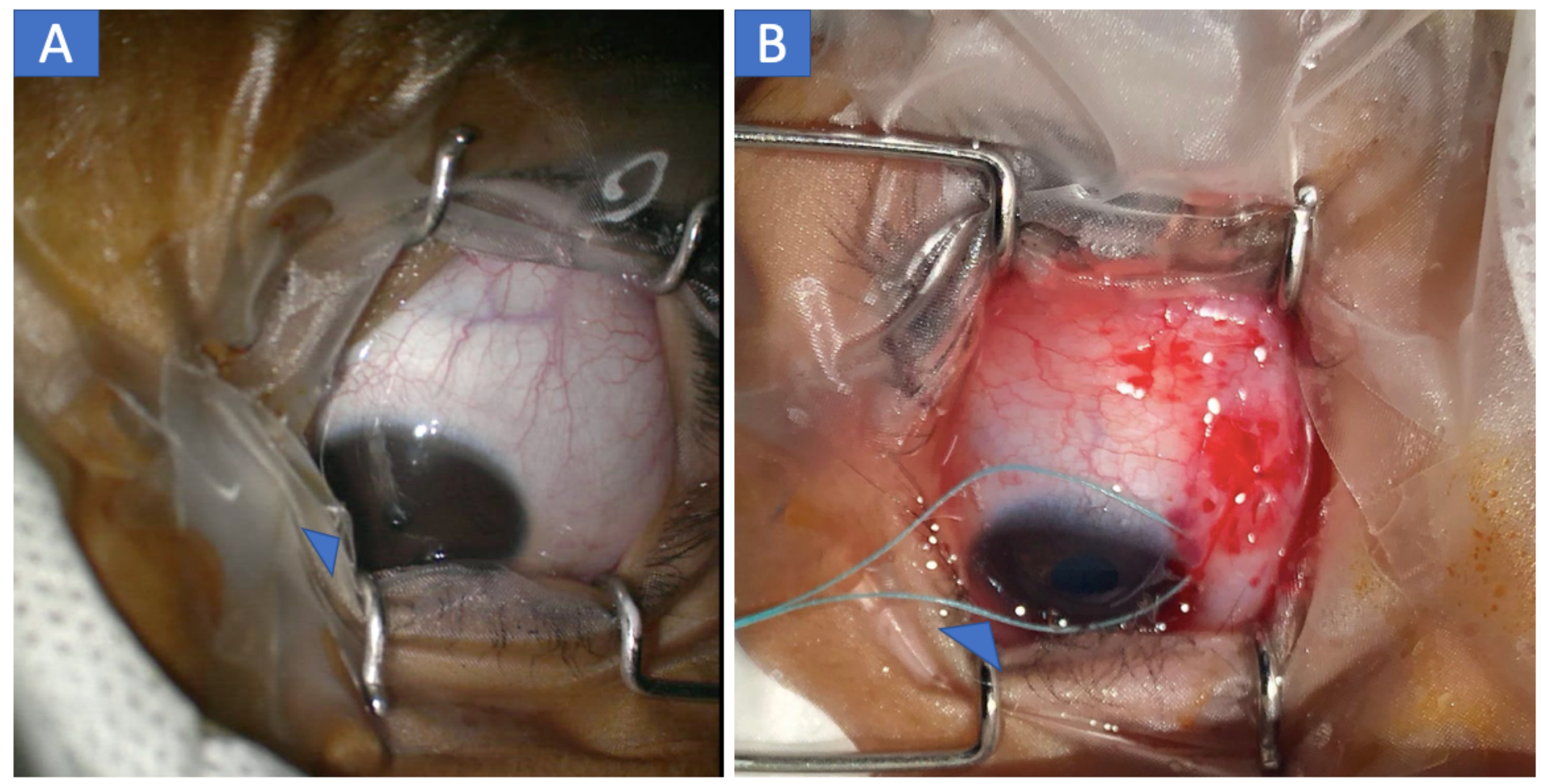

\section{Figure 1}

Photographs of eccentric eye positioning in downgaze with slight adduction (towards the nose) in (A) left eye before start of surgery in case 2 (infantile esotropia) with MAC1.6, BIS=34) (B) right eye during surgery in case 1 (infantile esotropia) with MAC 1.7, BIS=34. In case 1 down-drift was preceded by updrift $(\mathrm{MAC}=1.1, \mathrm{MAC}=55)$ when anesthetic depth was increased by increasing sevoflurane concentration. 

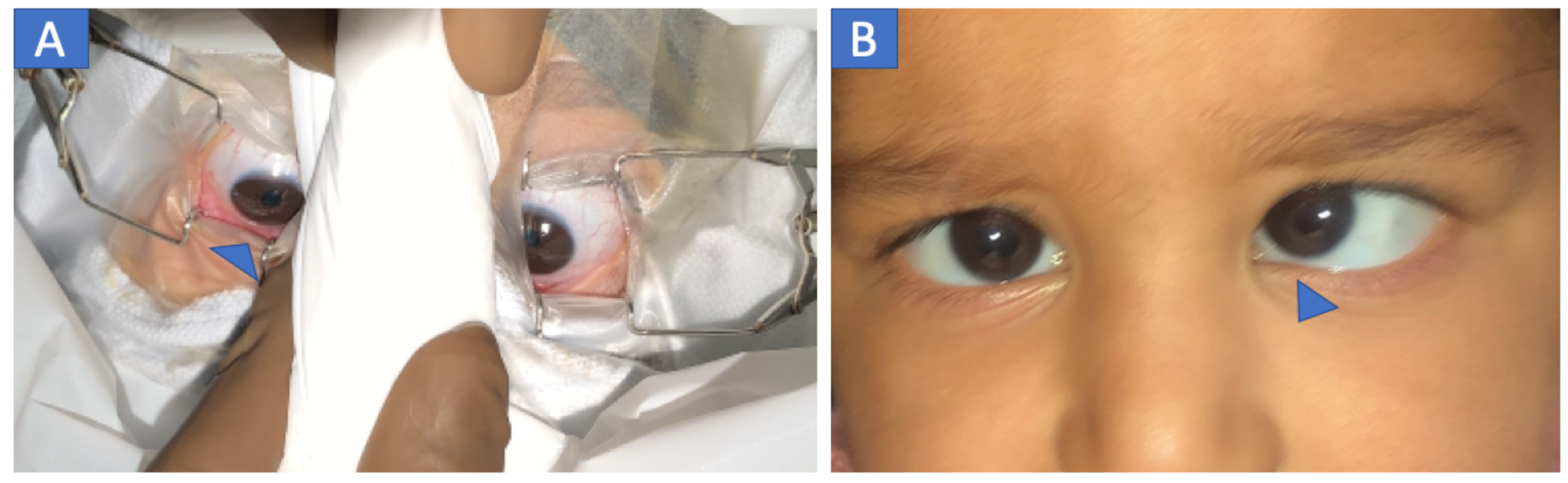

\section{Figure 2}

Pre-operative photograph of both eyes showing asymmetric down-positioning of eyes (MAC=2) in case 6 (infantile esotropia). Pre-operative profile of same patient showing esotropia with left eye Dissociated vertical deviation.
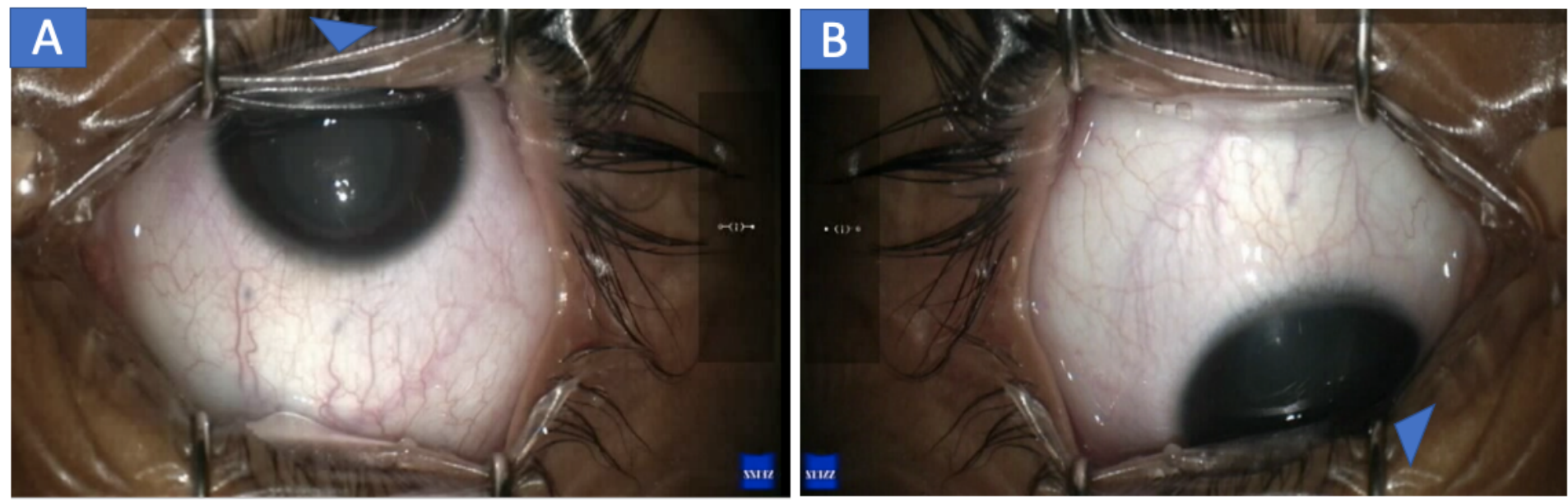

\section{Figure 3}

Photograph of the left eye of case7 (congenital cataract) showing upward eye drift before the start of surgery (MAC=1), following which sevoflurane concentration was increased and down-drift of eyes was experienced and eye assumed an eccentric position in downgaze (MAC=1.8) 

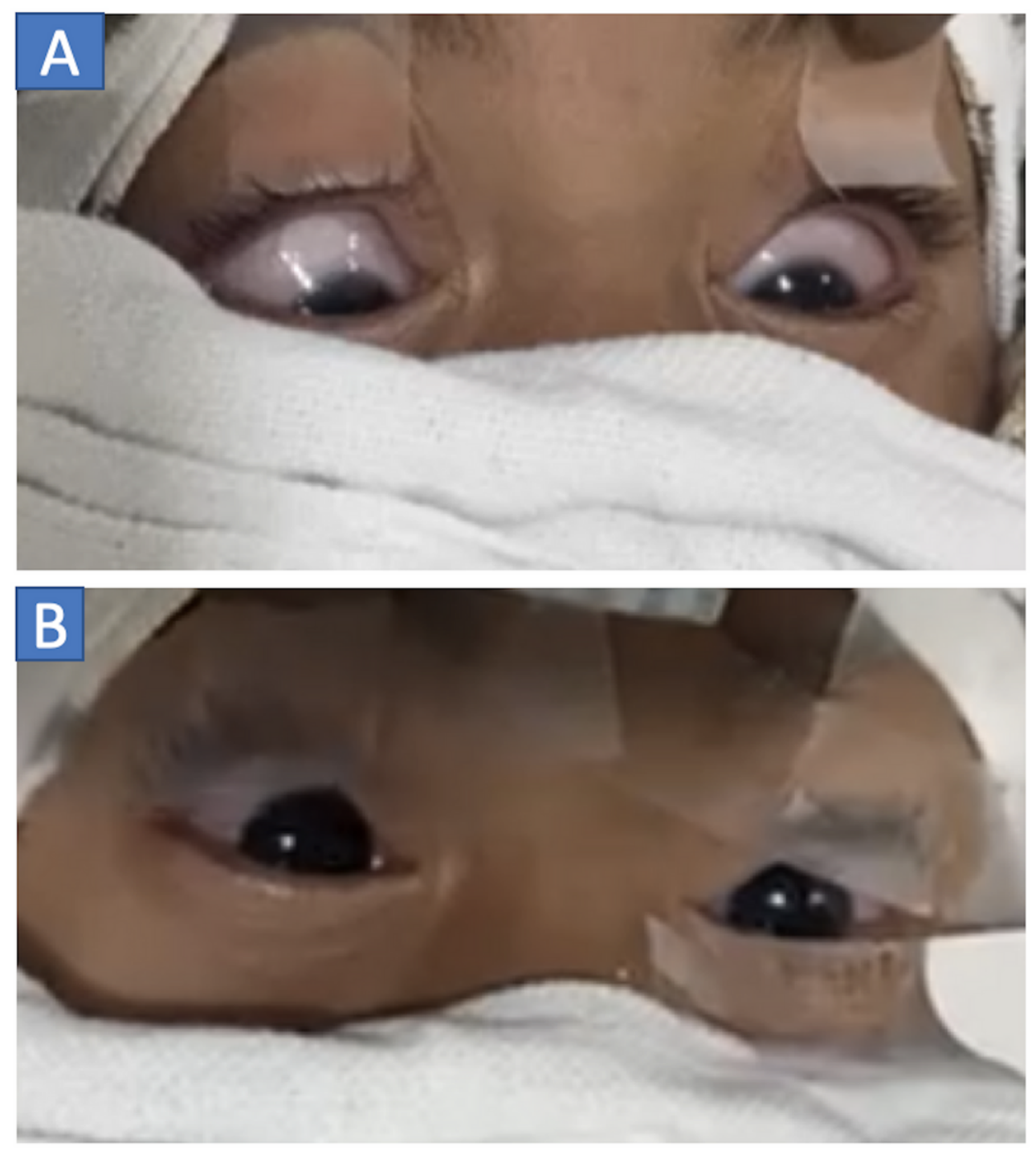

\section{Figure 4}

Pre-operative photograph of both eyes of case8 (before botox injection) showing (A) symmetric down-positioning of eyes before the start of surgery (MAC 1.4) when eyes were cleaned, draped, and opened following which sevoflurane concentration was decreased and (B) eyes returned to the central position (MAC=1.2) within a minute of decreasing sevoflurane concentration. It should be noted that recorded values of MAC at the time of intubation was 1.7 and MAC was stabilized to 1.4 within few minutes of decreasing sevoflurane concentration after intubation when eyes were opened to see their position at the time of cleaning and draping.

\section{Supplementary Files}

This is a list of supplementary files associated with this preprint. Click to download.

- video1.wmv

- video1.pdf

- video2.mp4

- video2.pdf

- video3.mp4

- video3.pdf 